\title{
Application of "Silk Road Culture" in City Square Landscape Design in Lanzhou City, Gansu Province, China
}

\author{
Xian-bin $\mathrm{ZHAO}^{1, *}$ \\ ${ }^{1}$ Lanzhou University of finance and economics institute of long bridge in China
}

Keywords: City Square, Silk Road culture, Landscape design.

\begin{abstract}
By analyzing the current situation of Lanzhou Dongfanghong Square, the article summarizes its advantages and disadvantages in landscape design. According to its existing problems, the solution is put forward and the square design method under the guidance of "Silk Road Culture". So that the landscape can be carried forward, the Chinese civilization can be demonstrated to promote the healthy and sustainable development of the city square landscape.
\end{abstract}

City Square refers to the part of social public land which is not occupied by houses and is connected with urban roads in the general layout of cities and towns. It is constructed in order to meet the needs of social life of various cities and enclosed by building, roads, landscapes, terrain and so on. City Square is composed of a variety of soft and hard landscape and using pedestrian traffic means. City Square is a certain theme and size of the node type of urban outdoor public space."[1] With the development of the times, our city needs more of the public square or cultural and leisure square. This kind of square is an activity and a place to win, simple and practical, embodies the soul of the city, reflecting the cultural characteristics of the city or region, to meet the psychological and emotional needs of the public at the same time, to create a rich social interaction. [2] In the environment of accelerating urbanization process in China, many city square constructions only focus on the visual style, grand and magnificent beauty of form, while ignoring the science and art of landscape plants. City Square is an important node in urban space [3], it should be like the ecological city, ecological building, living environment, people-oriented and other urban development concepts, into the new design concept.At present, the function of city square is more and more diversified, so the nature of the square is developing to the comprehensive direction [4]. City Square is the city's business card, shows the city's spirit every moment and reflects the harmony between man and nature, man and society, man and city[5].

\section{Overview of the Study Area}

The design area is located in Lanzhou City, Chengguan District, Dongfanghong Square. It easts Pingliang Road, west to 316 Road, north of the podium from the Taiwan Observatory, south to 360 Road, adjacent to the reunification of a building, the Office of Building II. The average north-south length of it is 638 meters; east-west width of it is 155 meters, with a total area of 92172 square meters. Lanzhou International Expo Center, Kuniyoshi Group and square podium, Lanzhou stadium form a "three pillars" (Figure 1). 


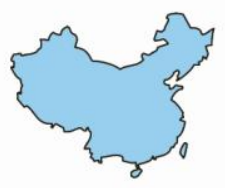

China

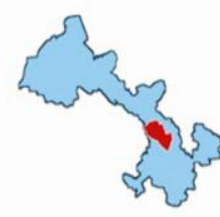

Gansu Province

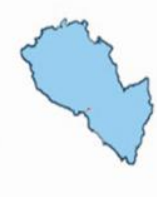

Lanzhou City

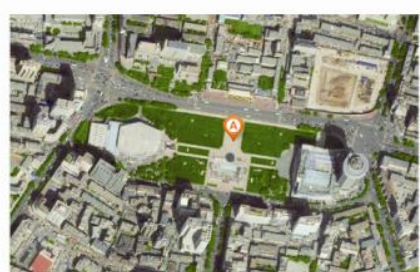

Dongfanghong Square

Figure 1. District Analysis

\section{Current Situation Analysis}

\section{Advantages}

Dongfanghong Square as the "meeting room" in Lanzhou City has been the "heart" of Lanzhou. Convenient traffic around the square, clear functional zoning and layout, it reflects the city center square features. It has great significance to develop the tourism in Lanzhou, to improve the investment environment and expand the visibility of Lanzhou.

\section{Disadvantages}

Since the middle of 1990s, China's urbanization and urban expansion has entered a stage of rapid development. Under this background, there are many problems in the construction of city square. On these imperfect aspects, it is easy to see almost the whole country from south to north, from east to west, monotonous, thousands of holes side of the model: In the government building as the background, the axis type, grass, looking up at the center of head sculpture, fountain square, overlooking the plant with ribbons, paving the lawn, step plus flagpole. It has become a new square stereotyped, boring monotonous, the lack of vitality". [6] Dongfanghong Square Lanzhou is builded in this context of the completion. After investigation and analysis, there are several major aspects of the problem:

Plant Configuration. The main green is lawn in Lanzhou Dongfanghong square and the lawn area is 36 thousand square meters. Lawn area accounted for $40.31 \%$ of the total square area, after planting the lawn requires a lot of water, which for the latter part of the landscape maintenance is costly in the arid climate of the north. Configure a single plant, the main tree species are Sophora japonica, cedar, spruce, generally speaking, the lack of large trees, no flowering shrubs, no flowers cause species failed to form a natural ecological communities.

Design Concept. Lack of design concept, without a clear design theme support, which also resulted in the lack of characteristics of this square, there is no distinctive landscape sketches to support the design theme. Dongfanghong Square, as the central square of Lanzhou City, should clearly reflect the history and culture of Lanzhou and its urban characteristics, as well as the Yellow River civilization, and the cultural embodiment of the Silk Road.

Hard Pavement. Square brick as the main hard pavement, although the overall pavement is harmony and unity, but it is lack of changes in hard pavement, and there is 
no certain attraction and can not attract the attention of tourists. Simple and gray pavement makes the entire region particularly monotonous.

Spatial Layout. The space layout is simple, it only has a large square, the rest of all are the green, this requirement is not consistent with people on the square function rich, diverse space in today's society.

\section{Design Theme}

Lanzhou Dongfanghong Square not only reflects the city building, culture, people and activities of these notable features, but also reflects the people Close to Nature and Regression. Lanzhou culture is the Yellow River civilization, Silk Road culture and the integration of the Northwest style, So as to highlight the characteristics of Lanzhou city, show characteristics of Silk Road culture, improve the functional structure and spatial layout of the city, respect for the basic needs of human nature as a prerequisite, transform Dongfanghong square in principle in principle to creating a real sense of the practical square. Combined with the excellent geographical location and cultural characteristics of Lanzhou, finally using "Silk Road culture" as the design theme (Figure 2).

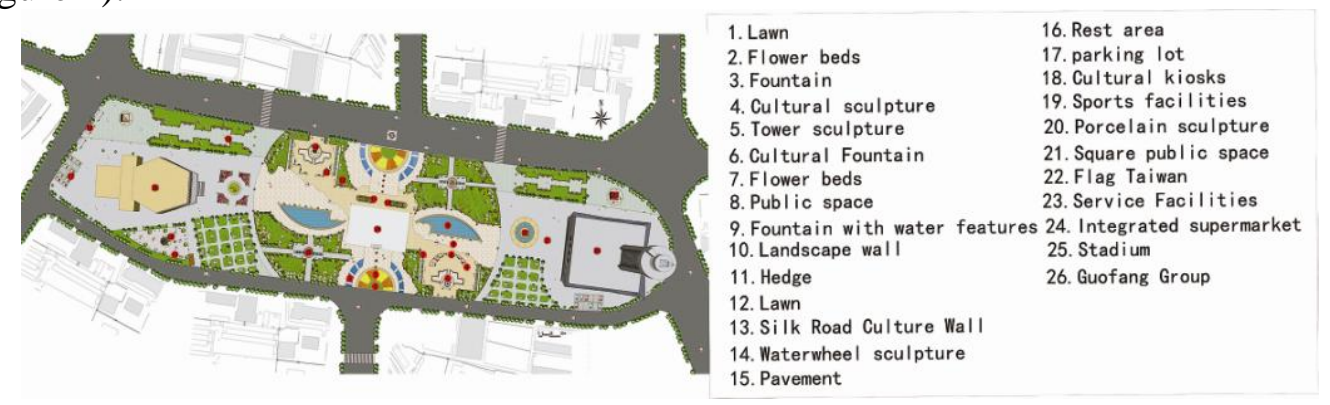

Figure 2.Design general plan

\section{Design Process}

\section{Design Analysis}

Function Partition. Due to the terrain factor of Dongfanghong Square, there are two main entrances and four sub-entrances, which are divided into square public space area, Silk Road cultural zone area, gymnasium public space area, Guofang Group public inter-area area, Activity area (Figure 3).

Landscape Structure Layout. The landscape layout of the square is dominated by the axis symmetry, with the central axis as the main landscape node, and gradually extended to the small landscape node; the main landscape node is the Silk Road cultural zone, in order to reflect the Silk Road culture in the square, so around the cultural belt design (Figure 4). 


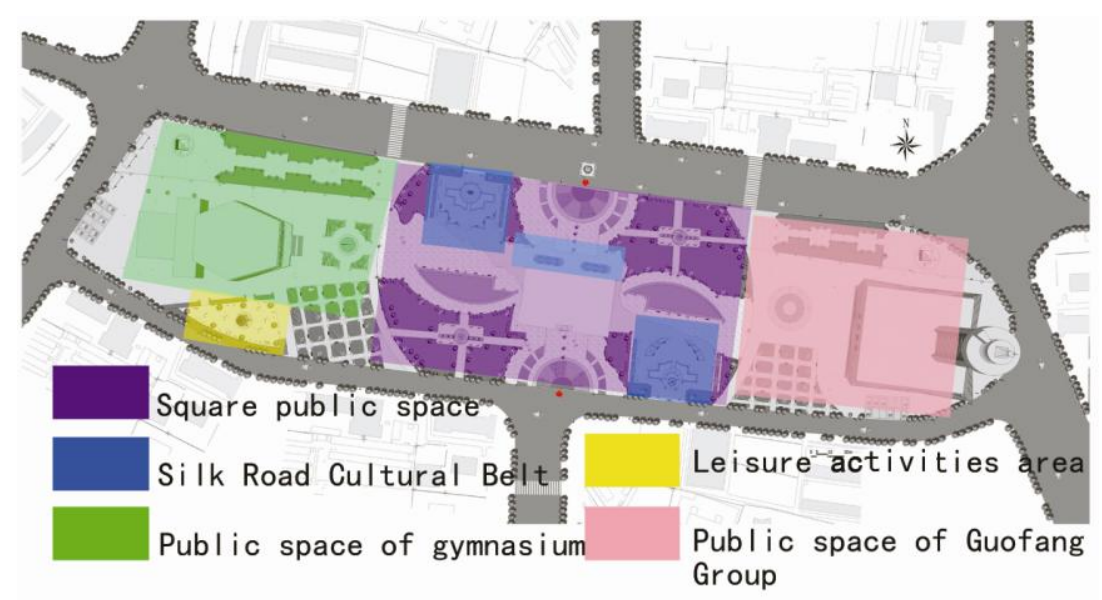

Figure 3.Functional Division

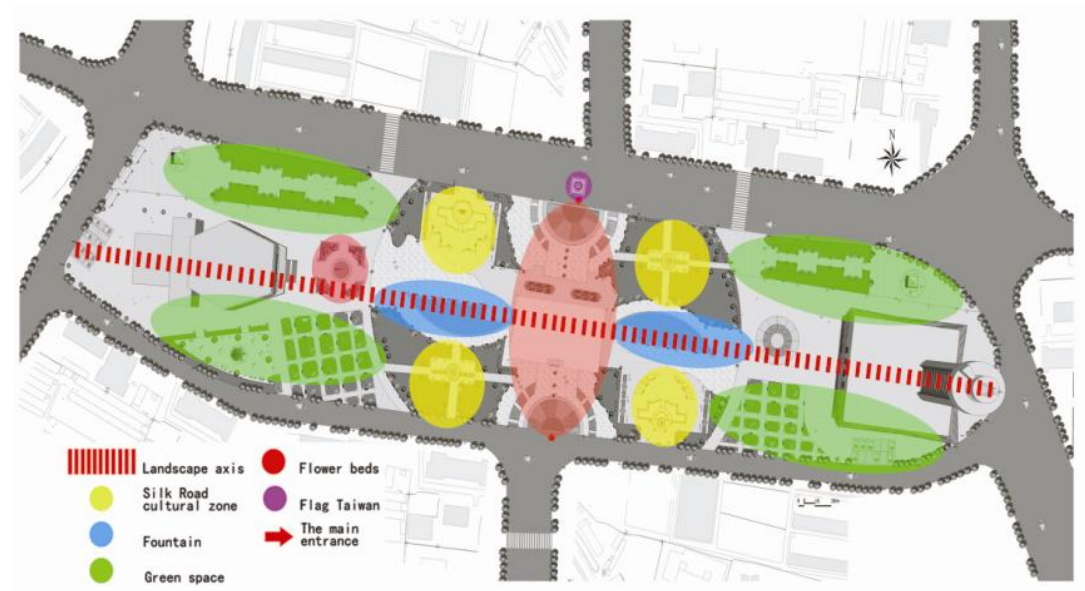

Figure 4. Landscape structure layout

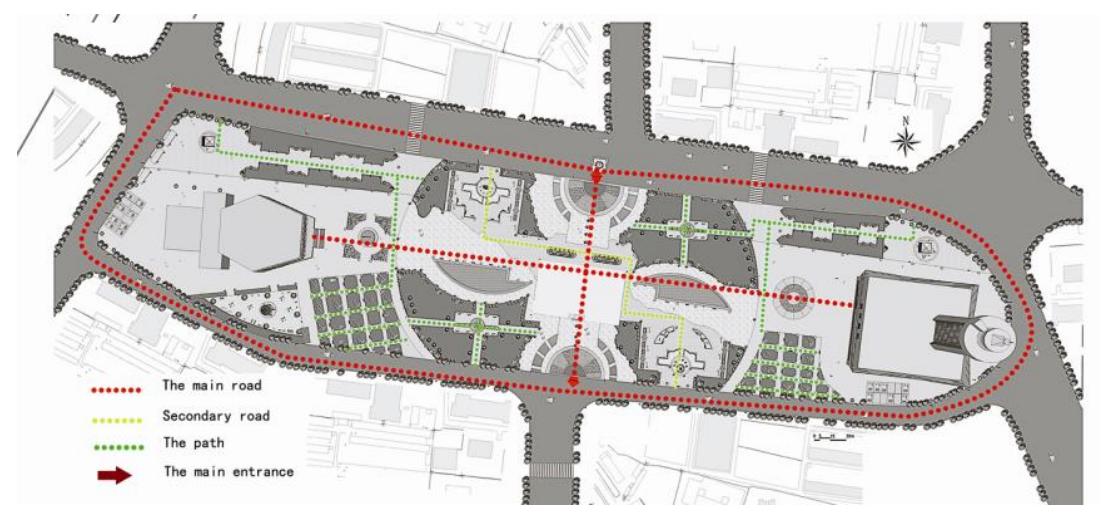

Figure 5. Road system design

The main view of the square is a symmetrical flower bed, fully display the color of the Oriental red Plaza. Silk Road cultural zone is the square on both sides of the landscape, in the cultural zone with the full using of the Silk Road cultural elements. The central axis is also surrounded by the use of cultural elements in the landscape nodes.

Road System Design. We often the use of terrain, buildings, plants or roads to space into a variety of different regions in landscape planning and the road to link the landscape into a whole at the same time. The roads in the square are mainly straight lines. (Figure 5) 
Silk Road Cultural Structure Design. The Silk Road culture embodied in several different spaces in the square. First of all, using culture in order to reflect the Silk Road culture at the entrance. Next is the public space of the square, In the public event space I will use the Silk Road cultural elements of the sculpture in which fully embodies the Silk Road cultural characteristics, In the leisure area I also added a proper cultural elements (Figure 6).

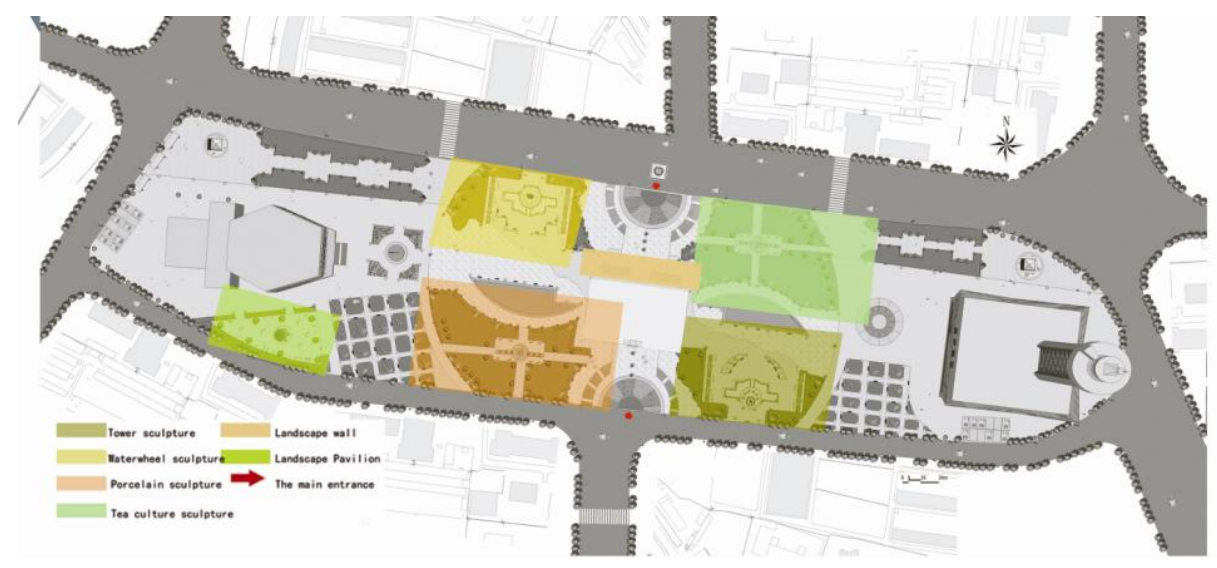

Figure 6. Silk road cultural structure design

Plant Configuration. By placing the flower bed that containing the Silk Road cultural identity to reflect the culture of the Silk Road in the main road and the entrance. Flower beds, flower boxes are planted chrysanthemum, rose, tulip on the square. The main species are evergreen trees and deciduous trees. Through vivid colors and undulating plants, forming a patchwork of contour lines. The plant selection highlights the characteristics of Lanzhou, the plant uses cedar, Sophora japonica, gold willow, as the square of the key species, accompanied by Camphor, Lobular boxwood, Acacia, Spring, Rose, Tulips and other flowers.

\section{The Application of "Silk Road Culture" in the Landscape Planning and Design in Dongfanghong Square.}

The Expression of "Silk Road Culture" in the Cultural. We use the Silk Road route in Gansu Province as the shape of culture. The first is the Dunhuang, Dunhuang is an important juncture, so we use tower sculptures On behalf of Dunhuang on the entrance (Figure 7); Then Jiayuguan, Jiayuguan holds the Silk Road Music Culture Festival every year which can fully reflect the importance of the Silk Road culture. So we put landscape fountain with notes in the second node (Figure 8). The third node is Zhangye, the fourth node is Wuwei, with a group of landscape walls which content for the Silk Road camel connected together show that the camel is an important bridge in the ancient Silk Road culture of communication (Figure 9). The fifth node is Lanzhou, using water sculpture to express the characteristics of Lanzhou (Figure 10). The five cities together which have an important role in the Silk Road form a Silk Road cultural zone. 


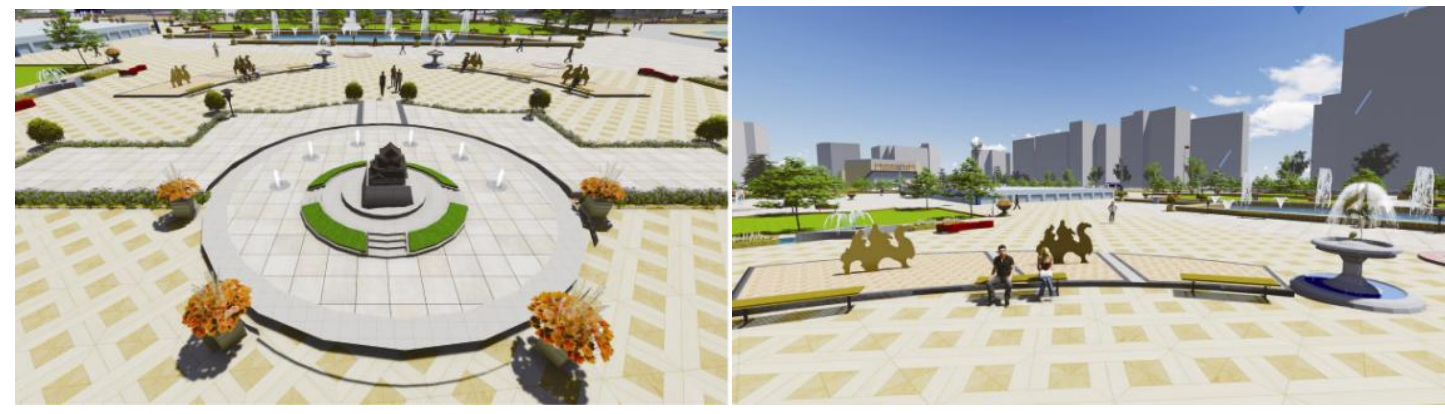

Figure 7.Tower sculpture

Figure 8 . The music fountain

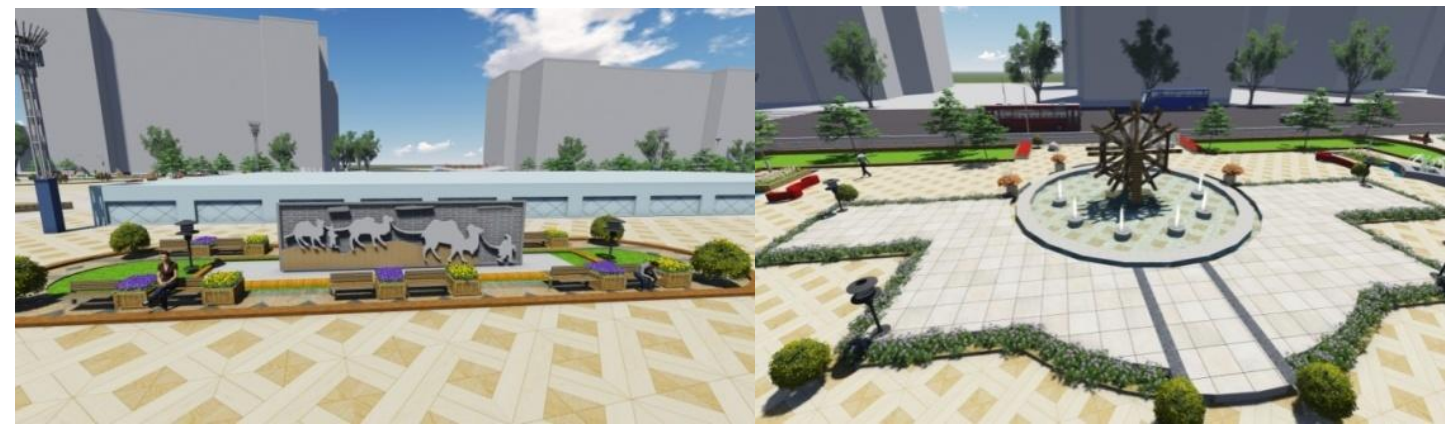

Figure 9.Silk Road Camel

Figure 10.Waterwheel

The Expression of "Silk Road Culture" in Public Space. In Public Space, Multicolored silk, tea culture, Chinese porcelain have made important contributions for the ancient East-West economic and cultural exchanges. So I add a porcelain sculpture in the public space on the left side of the square (Figure 11) to reflect the porcelain in the Silk Road culture and add a teapot sculpture (Figure 12) to reflect the Silk Road culture In the right of the public space.

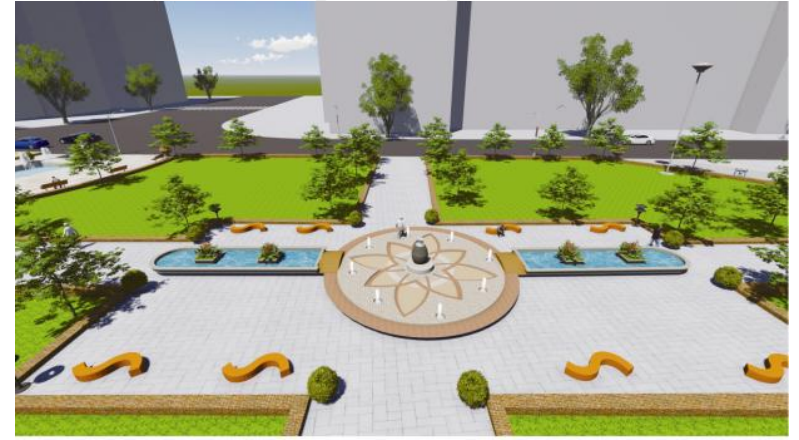

Figure 11. Porcelain culture sculpture

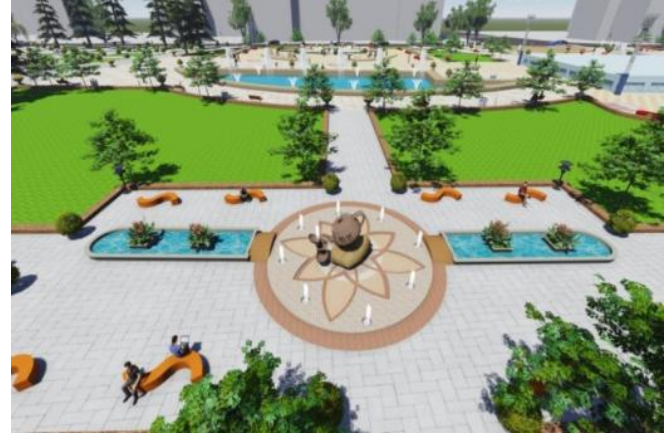

Figure 12. Tea culture sculpture

The Expression of "Silk Road Culture" in Recreational. In the public space, In order to express Silk Road culture we use a Western-style Western style pavilion, because the Silk Road is a main road which can communicate economic, political and cultural between the East and the West. This channel connects the Central Plains, the Western Regions, Arabia and the Persian Gulf close. After several centuries of continuous efforts, the Silk Road extended westward to the Mediterranean, So using a Western pavilion in the leisure area (Figure 13). 


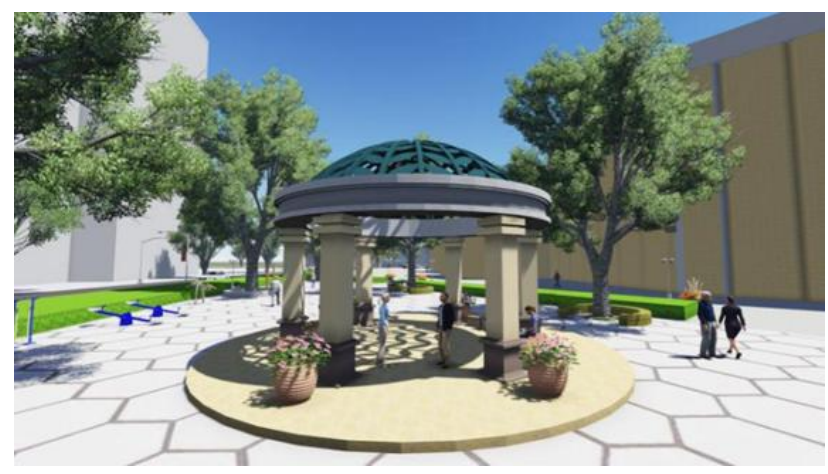

Figure 13. Western style pavilion

\section{Conclusion}

The design is Lanzhou Dongfanghong Square, the key of the design is that the square should meet the function of Interactive, participatory experience area between Lanzhou people and landscape. We should create a "Silk Road culture" as the main commemorative square in the form. This project is designed to provide a city living room with a historical, to the Yellow River civilization, Silk Road culture and integration of the Northwest style as a whole for Lanzhou residents.

\section{Reference}

[1] Wang Ke, Xia Jian, Yang Haixin. Ed, "city square design", Southeast University press, 1999

[2] BAI Chen-yang. City planning and design of urban square [J]. Chinese Garden, 2001.1: 54 .

[3] Meng Jin, Chen Liang. City Square landscape design creative practice [J]. Anhui Agricultural Sciences, 2010, 38: 7072-7074.

[4] Cai Yongjie. City Square [M]. Nanjing: Southeast University Press, 2006: 80-91.

[5] Zheng Shujing, Xu Xianliang, Yao Lianfang. Sightseeing agriculture environment --- the beauty of the landscape in the planning [J] Guangdong Garden, 2009 (2): 40-42.

[6] Liu Xiushen. Construction Image • Urban Design • City Square [J]. Chinese Garden, 2001, (1). 